\title{
Evaluation of Magnetic and Thermal Properties of Ferrite Nanoparticles for Biomedical Applications
}

\author{
Asahi Tomitaka ${ }^{1 *}$, Minhong Jeun ${ }^{2}$, Seongtae $\mathrm{Bae}^{2}$, and Yasushi Takemura ${ }^{1}$ \\ ${ }^{1}$ Department of Electrical and Computer Engineering, Yokohama National University, Yokohama, Japan \\ ${ }^{2}$ Biomagnetics Laboratory, Department of Electrical and Computer Engineering, National University of Singapore, Singapore
}

(Received 20 April 2011, Received in final form 22 May 2011, Accepted 29 May 2011)

\begin{abstract}
Magnetic nanoparticles can potentially be used in drug delivery systems and for hyperthermia therapy. The applicability of $\mathrm{Fe}_{3} \mathrm{O}_{4}, \mathrm{CoFe}_{2} \mathrm{O}_{4}, \mathrm{MgFe}_{2} \mathrm{O}_{4}$, and $\mathrm{NiFe}_{2} \mathrm{O}_{4}$ nanoparticles for the same was studied by evaluating their magnetization, thermal efficiency, and biocompatibility. $\mathrm{Fe}_{3} \mathrm{O}_{4}$ and $\mathrm{CoFe}_{2} \mathrm{O}_{4}$ nanoparticles exhibited large magnetization. $\mathrm{Fe}_{3} \mathrm{O}_{4}$ and $\mathrm{NiFe}_{2} \mathrm{O}_{4}$ nanoparticles exhibited large induction heating. $\mathrm{MgFe}_{2} \mathrm{O}_{4}$ nanoparticles exhibited low magnetization compared to the other nanoparticles. $\mathrm{NiFe}_{2} \mathrm{O}_{4}$ nanoparticles were found to be cytotoxic, whereas the other nanoparticles were not cytotoxic. This study indicates that $\mathrm{Fe}_{3} \mathrm{O}_{4}$ nanoparticles could be the most suitable ones for hyperthermia therapy.
\end{abstract}

Keywords : magnetic nanoparticle, drug delivery systems, hyperthermia, cytotoxicity

\section{Introduction}

Nanoparticles have several potential biomedical applications, since they are compatible in size. Protein molecules are $(5-50 \mathrm{~nm})$ and segmented DNA molecules (2 $\mathrm{nm} \times(10-100 \mathrm{~nm})$ [1]. Nanoparticles are particularly promising as carriers in drug delivery systems for treating cancer because of the enhanced permeability and retention (EPR) effect. The EPR effect refers to the phenomenon of enhanced extravasations of macromolecules from tumor blood vessels and the retention of these macromolecules in tumor tissues; the same is not observed in normal vasculature [2]. Magnetic nanoparticles can be utilized not only as carriers for drug delivery systems but also as heat sources for hyperthermia therapy. Hyperthermia therapy is a heat treatment for cancer that poses a low risk to the body and causes few side effects as compared to surgery, chemotherapy, and radiation therapy. Hyperthermia therapy can also be administered repeatedly. Magnetic nanoparticles have attractive properties such as magnetic guidance and induction heating in an ac magnetic field. Thus, magnetic nanoparticles enable combination therapy involving drug delivery systems and hyperthermia. Ferrite nanoparticles are suitable materials

\footnotetext{
*Corresponding author: Tel: +81-45-339-4151
}

Fax: +81-45-339-4154, e-mail: takemura@ynu.ac.jp for biomedical applications because of their wide range of size, diversity, and chemical stability as compared to metal nanoparticles [3]. $\mathrm{Fe}_{3} \mathrm{O}_{4}$ and $\gamma-\mathrm{Fe}_{2} \mathrm{O}_{3}$ nanoparticles have been explored extensively from the viewpoint of their biocompatibility [4]; however, for other ferrite nanoparticles there have been only a few reports on their induction heating ability and cytotoxicity $[5,6]$. The size dependence of the magnetic and thermal property and the ac magnetic property of $\mathrm{NiFe}_{2} \mathrm{O}_{4}$ nanoparticles $(7.7 \mathrm{~nm}$ and $242 \mathrm{~nm}$, respectively) have been reported [7, 8]. In this study, the applicability of various ferrite nanoparticles as drug delivery systems and for hyperthermia therapy is investigated by evaluating their magnetic characterization, thermal properties, and cytotoxicity.

\section{Experiments}

$\mathrm{Fe}_{3} \mathrm{O}_{4}, \mathrm{CoFe}_{2} \mathrm{O}_{4}, \mathrm{MgFe}_{2} \mathrm{O}_{4}$, and $\mathrm{NiFe}_{2} \mathrm{O}_{4}$ nanoparticles having various sizes were prepared in a dried powder state. $\mathrm{Fe}_{3} \mathrm{O}_{4}$ and $\mathrm{NiFe}_{2} \mathrm{O}_{4}$ nanoparticles (particle size: 20$30 \mathrm{~nm}$ ) were purchased from Nanostructured \& Amorphous Materials, Inc.; other nanoparticles were synthesized using the newly modified sol-gel method [9]. The mean size and deviation of the nanoparticle are listed in Table 1. The samples except $\mathrm{NiFe}_{2} \mathrm{O}_{4}(20-30 \mathrm{~nm})$ was supplied to magnetic and thermal characterization studies. The $\mathrm{dc}$ magnetization curve of the major loop was measured 
Table 1. The average particle sizes and distributions of the particles were determined by a high resolution transmission electron microscopy (HRTEM) and a field emission electron microscopy (FESEM).

\begin{tabular}{ll}
\hline \hline Material & Size $[\mathrm{nm}]$ \\
\hline $\mathrm{Fe}_{3} \mathrm{O}_{4}$ & $20-30$ \\
$\mathrm{CoFe}_{2} \mathrm{O}_{4}$ & $26.5 \pm 6.1,32.7 \pm 7.3,146.1 \pm 39.3$ \\
$\mathrm{MgFe}_{2} \mathrm{O}_{4}$ & $27.4 \pm 9.2,34.4 \pm 16.1,130.2 \pm 40.7$ \\
$\mathrm{NiFe}_{2} \mathrm{O}_{4}$ & $20-30,24.8 \pm 6.3,32.8 \pm 8.6,130.7 \pm 44.9$ \\
\hline
\end{tabular}

using a vibrating sample magnetometer (VSM) at room temperature with a maximum field of $10 \mathrm{kOe}$. The thermal property of the particles was measured by applying an ac magnetic field. The field strength was varied from 50 to $500 \mathrm{Oe}$, and the frequency was fixed at $10 \mathrm{kHz}$. In the magnetic and thermal characterization studies, $60 \mathrm{mg}$ of each sample was used in the dried state. A cytotoxicity study of $\mathrm{Fe}_{3} \mathrm{O}_{4}(20-30 \mathrm{~nm}), \mathrm{CoFe}_{2} \mathrm{O}_{4}(26.5 \pm 6.1 \mathrm{~nm})$, $\mathrm{MgFe}_{2} \mathrm{O}_{4}(27.4 \pm 9.2 \mathrm{~nm})$, and $\mathrm{NiFe}_{2} \mathrm{O}_{4}(20-30 \mathrm{~nm})$ nanoparticles was conducted on human cervical carcinoma cells (HeLa cells). HeLa cells were cultured in Dulbecco's modified eagle medium (DMEM; GIBCO) with 10\% fetal bovine serum (Equitec-bio, Inc.) and 1\% penicillin streptomycin (GIBCO); they were then incubated at $37^{\circ} \mathrm{C}$ in a $5 \% \mathrm{CO}_{2}$ atmosphere. HeLa cells were seeded at a density of $2 \times 10^{4}$ cells/well in a 24-well plate and incubated at $37^{\circ} \mathrm{C}$ in a $5 \% \mathrm{CO}_{2}$ atmosphere. After 24 hours of incubation, HeLa cells were exposed to $200 \mu \mathrm{g} / \mathrm{ml}$ of each nanoparticle dispersed in the medium. The cell viability was measured for 4 days. The relative ratio of the cells treated with and without magnetic nanoparticles was calculated by the following equation:

Relative ratio $[\%]=$ number of cells treated with nano-

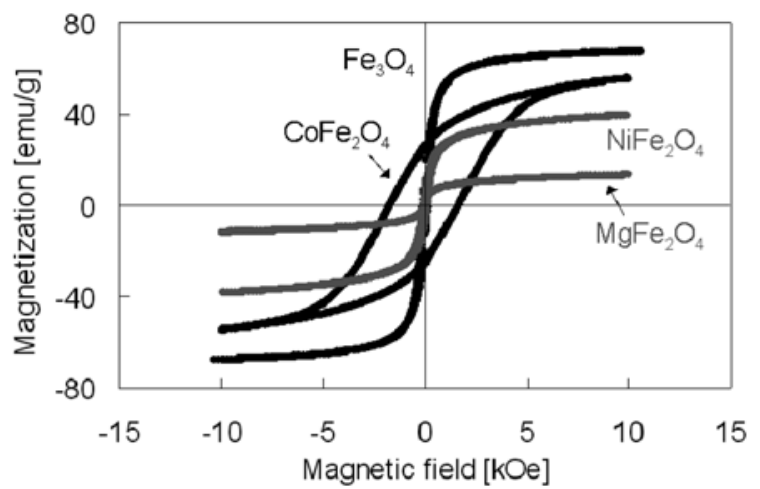

Fig. 1. Hysteresis loops of $\mathrm{Fe}_{3} \mathrm{O}_{4}(20-30 \mathrm{~nm}), \mathrm{CoFe}_{2} \mathrm{O}_{4}(26.5 \pm$ $6.1 \mathrm{~nm}), \mathrm{MgFe}_{2} \mathrm{O}_{4}(27.4 \pm 9.2 \mathrm{~nm})$, and $\mathrm{NiFe}_{2} \mathrm{O}_{4}(24.8 \pm 6.3$ $\mathrm{nm})$ measured by a vibrating sample magnetometer at room temperature with the maximum applied field of $10 \mathrm{kOe}$. particles [cells]/number of cells treated without nanoparticles [cells]

\section{Results and Discussion}

\subsection{Magnetic properties}

Fig. 1 shows the hysteresis curves of $\mathrm{Fe}_{3} \mathrm{O}_{4}(20-30 \mathrm{~nm})$, $\mathrm{CoFe}_{2} \mathrm{O}_{4}(26.5 \pm 6.1 \mathrm{~nm}), \mathrm{MgFe}_{2} \mathrm{O}_{4}(27.4 \pm 9.2 \mathrm{~nm})$, and $\mathrm{NiFe}_{2} \mathrm{O}_{4}(24.8 \pm 6.3 \mathrm{~nm})$ as measured using a VSM at room temperature. The magnetic properties of the samples

(a)

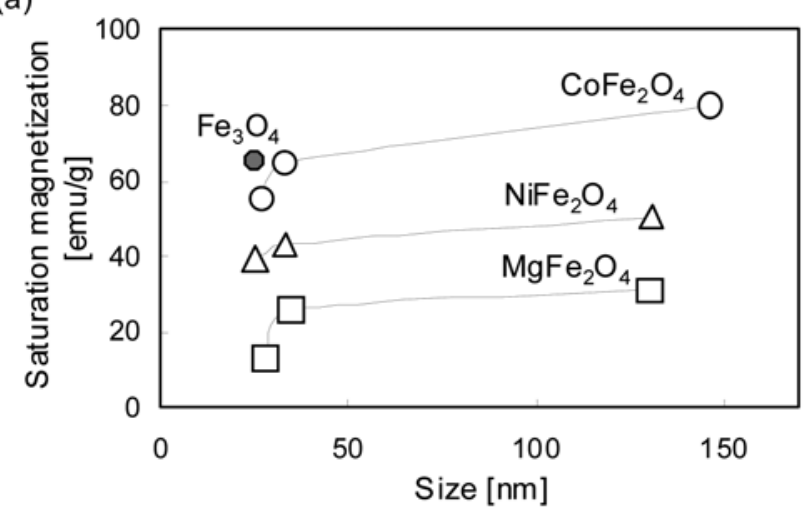

(b)

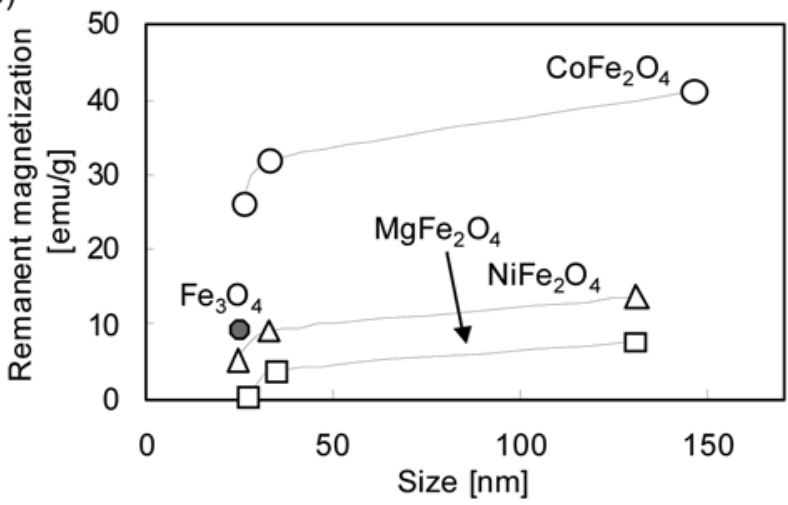

(c)

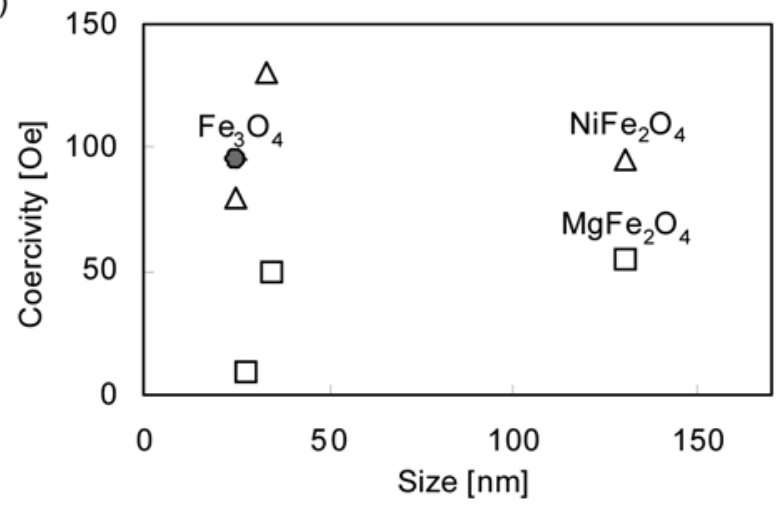

Fig. 2. Magnetic characterization of samples measured by a vibrating sample magnetometer at room temperature with the maximum applied field of $10 \mathrm{kOe}$. (a) saturation magnetization, (b) remanent magnetization, and (c) coercivity. 
clearly exhibited material dependence. The saturation and remanent magnetizations of all samples listed in Table 1 are shown in Figs. 2(a) and (b), respectively. The coercivity of all samples except for the $\mathrm{CoFe}_{2} \mathrm{O}_{4}$ nanoparticles is shown in Figs. 2(c). The coercivity of $\mathrm{CoFe}_{2} \mathrm{O}_{4}$ at 26.5 $\mathrm{nm}, 32.7 \mathrm{~nm}$, and $146.1 \mathrm{~nm}$ was $1720 \mathrm{Oe}, 1570 \mathrm{Oe}$, and 1030 Oe, respectively. Fig. 2(a) shows that the smaller particles exhibited smaller saturation magnetization. Similar reduced saturation magnetization of various ferrite nanoparticles has been reported in some papers [7, 10-12]. This reduced magnetization of magnetic nanoparticles can be explained by the existence of a nonmagnetic layer as a surface dead layer [13]. The saturation magnetization of $\mathrm{CoFe}_{2} \mathrm{O}_{4}$ is comparable to that of $\mathrm{Fe}_{3} \mathrm{O}_{4}$ and is greater than that of the other nanoparticles. Figs. 2(b) and (c) show that $\mathrm{CoFe}_{2} \mathrm{O}_{4}$ exhibits much larger remanent magnetization and coercivity than the other nanoparticles because of its large anisotropy. The coercivity largely depends on the anisotropy of the material. The coercivity of the samples was shown to be strongly size-dependent. In multi-domain particles, magnetization reversal occurs because of domain wall movement. As domain walls move through a particle, they are pinned at grain boundaries; additional energy is required for the domain walls to continue moving. Therefore, reducing the particle size creates more pinning sites and increases the coercivity of multi-domain nanoparticles [14]. In single-domain particles, the higher coercivity of nanoparticles can be attributed to the demagnetization caused by domain rotation, which requires greater energy than the domain wall movement of multi-domain particles [12]. Therefore, the coercivity of single-domain nanoparticles increases with their size. The coercivities of $\mathrm{MgFe}_{2} \mathrm{O}_{4}$ and $\mathrm{NiFe}_{2} \mathrm{O}_{4}$ nanoparticles correspond to these reports.

\subsection{Thermal properties}

The temperature rise of all samples listed in Table 1 in an ac magnetic field is shown in Fig. 3. The temperature rise of the samples is indicated by $\Delta T / \Delta t$ at $t \approx 0$, the initial slope for time dependence, where $T$ and $t$ are the measured temperature and time, respectively. Only hysteresis loss was assumed to contribute to the heat generated by the nanoparticles because of the low frequency $(10 \mathrm{kHz})$. Fig. 3(a) shows that $\mathrm{Fe}_{3} \mathrm{O}_{4}(20-30$ $\mathrm{nm}$ ) nanoparticles exhibited the highest temperature rise as compared to the other nanoparticles because it had the highest magnetization. Fig. 3(b) shows that $\mathrm{CoFe}_{2} \mathrm{O}_{4}$ nanoparticles exhibited the lowest temperature rise and that the slope increased exponentially with the magnetic field strength. This was because of the high coercivity of (a)

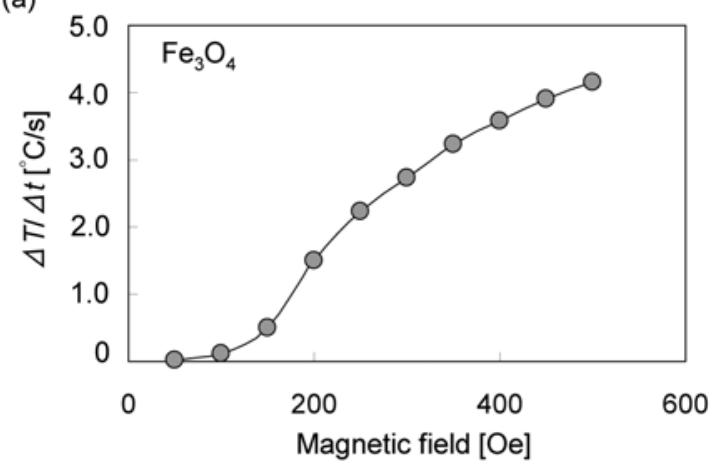

(c)

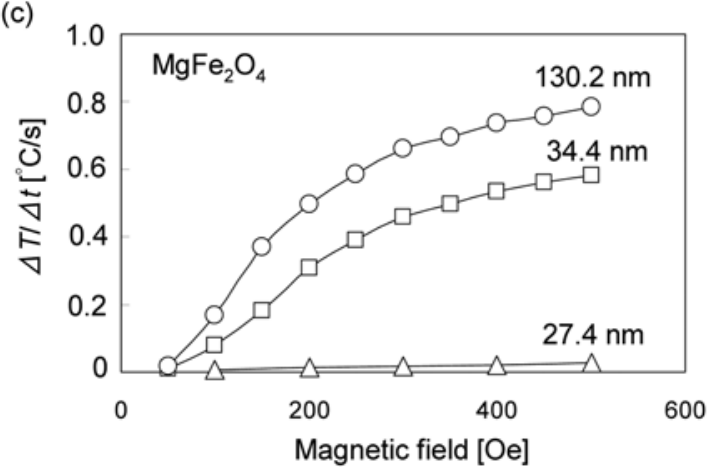

(b)

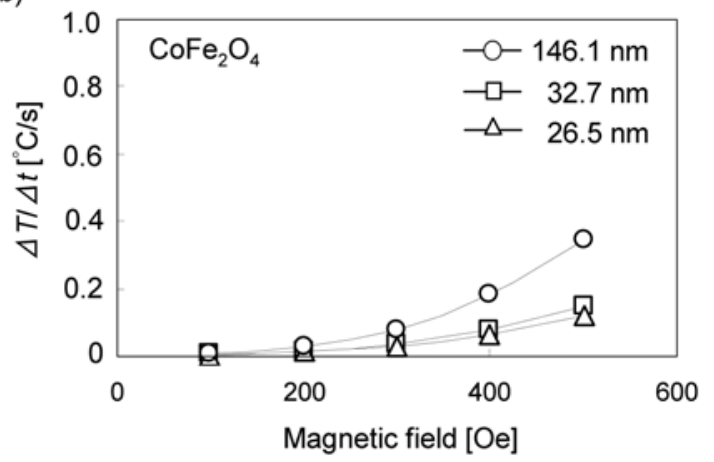

(d)

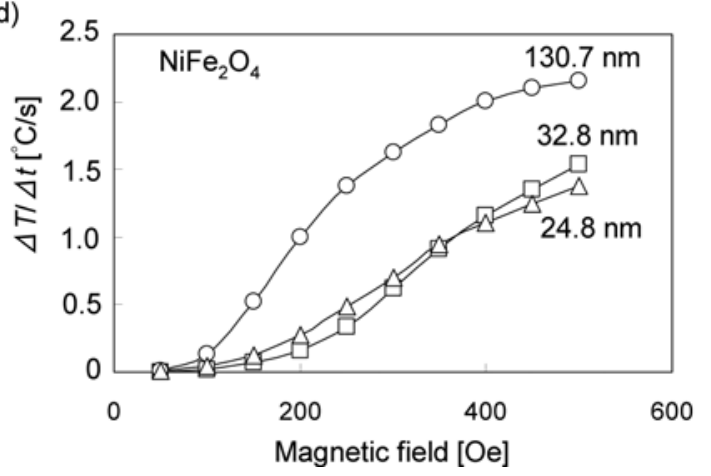

Fig. 3. Magnetic field strength dependence of induction heating. The induction heating was indicated by $\Delta T / \Delta t$ at $t \approx 0$, its initial slope for time dependence, where $T$ and $t$ are the measured temperature and time, respectively. The ac field frequency was $10 \mathrm{kHz}$ and amplitude was varied from 50 to 500 Oe. (a) $\mathrm{Fe}_{3} \mathrm{O}_{4}$, (b) $\mathrm{CoFe}_{2} \mathrm{O}_{4}$, (c) $\mathrm{MgFe}_{2} \mathrm{O}_{4}$, and (d) $\mathrm{NiFe}_{2} \mathrm{O}_{4}$. 
(a)

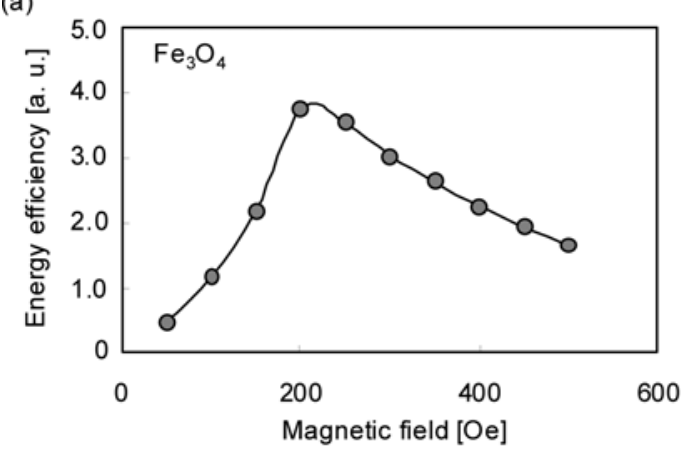

(c)

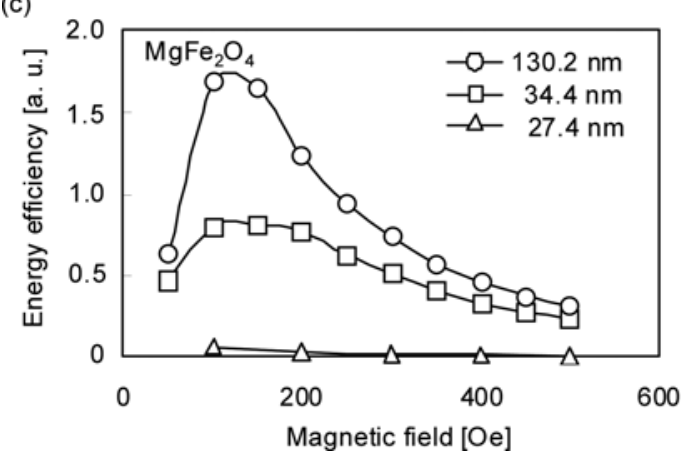

(b)

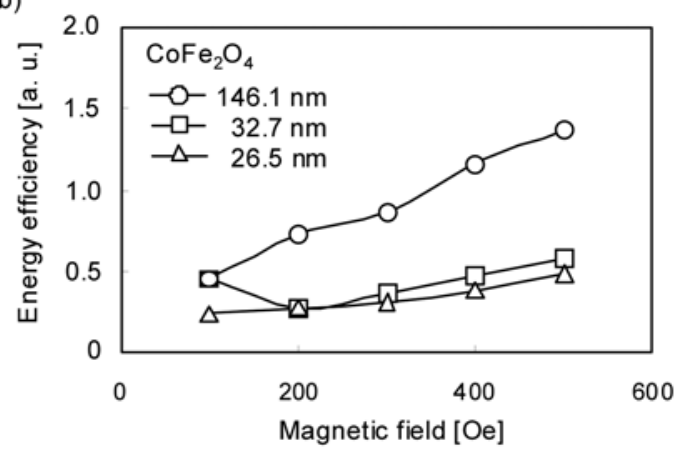

(d)

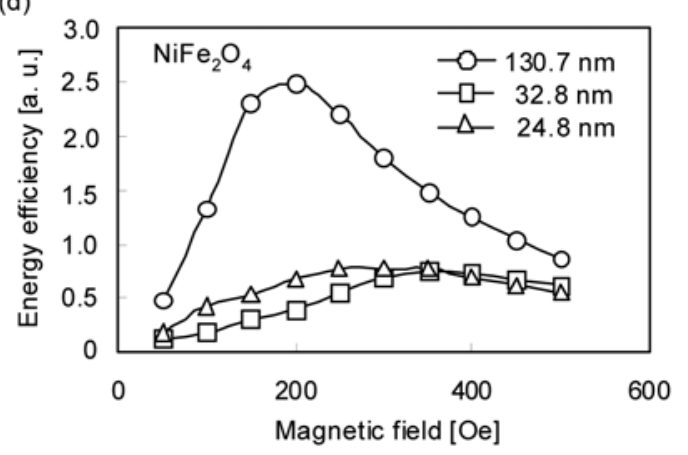

Fig. 4. Efficiency of applied energy utilized to generate induction heating, plotted as a function of applied magnetic field. The efficiency is defined by temperature rise divided by $H^{2} \times f$, where $H$ and $f$ are the amplitude and frequency, respectively, of the applied ac magnetic field. (a) $\mathrm{Fe}_{3} \mathrm{O}_{4}$, (b) $\mathrm{CoFe}_{2} \mathrm{O}_{4}$, (c) $\mathrm{MgFe}_{2} \mathrm{O}_{4}$, and (d) $\mathrm{NiFe}_{2} \mathrm{O}_{4}$.

the $\mathrm{CoFe}_{2} \mathrm{O}_{4}$ nanoparticles (larger than $1000 \mathrm{Oe}$ ). Fig. 3(c) shows that the temperature rise of $\mathrm{MgFe}_{2} \mathrm{O}_{4}(130.2$ $\mathrm{nm}$ ) was higher than that of the $34.4 \mathrm{~nm}$ and $27.4 \mathrm{~nm}$ samples because of its higher magnetization and coercivity. In contrast, $\mathrm{MgFe}_{2} \mathrm{O}_{4}(27.4 \mathrm{~nm})$ exhibited a lower temperature rise because of its extremely low coercivity $(10 \mathrm{Oe})$. Fig. 3(d) shows that the temperature rise of $\mathrm{NiFe}_{2} \mathrm{O}_{4}(130.7 \mathrm{~nm})$ was higher than that of the $32.8 \mathrm{~nm}$ and $24.8 \mathrm{~nm}$ samples, as in the case of $\mathrm{MgFe}_{2} \mathrm{O}_{4}$. The temperature rise of the $32.8 \mathrm{~nm} \mathrm{NiFe}_{2} \mathrm{O}_{4}$ was lower than that of the $24.8 \mathrm{~nm} \mathrm{NiFe} \mathrm{O}_{4}$ when the field strength was less than 400 Oe and higher than that of the $24.8 \mathrm{~nm}$ $\mathrm{NiFe}_{2} \mathrm{O}_{4}$ when the field strength was greater than 400 Oe. This was because of the different coercive forces of 32.8 $\mathrm{nm}$ and $24.8 \mathrm{~nm} \mathrm{NiFe} \mathrm{O}_{4}$ at 80 Oe and 130 Oe, respectively. The hysteresis losses of magnetic nanoparticles depend on their coercive forces. Energy efficiency of applied energy to generate induction heating is shown in Fig. 4. The energy efficiency is determined by the temperature rise divided by $H^{2} \times f$, where $H$ and $f$ are the amplitude and frequency, respectively, of the applied ac magnetic field. The energy applied to generate a magnetic field is proportional to the product of $H^{2}$ and $f$. Fig. 4 shows that the optimum field strength of $\mathrm{Fe}_{3} \mathrm{O}_{4}$ (20-30 $\mathrm{nm}$ ) is $200 \mathrm{Oe}$; $27.4 \mathrm{~nm}$ and $34.4 \mathrm{~nm} \mathrm{MgFe}_{2} \mathrm{O}_{4}$ is 100 -
$150 \mathrm{Oe}$; and $24.8 \mathrm{~nm}, 32.8 \mathrm{~nm}$, and $130.7 \mathrm{~nm} \mathrm{NiFe}_{2} \mathrm{O}_{4}$ is 250-300 Oe, $350 \mathrm{Oe}$, and 150-200 Oe, respectively. The optimum field strength of $\mathrm{CoFe}_{2} \mathrm{O}_{4}$ samples could not be determined because the temperature rise of these samples continued within a field strength of 50-500 Oe. Nanoparticles with lower coercivity, such as $\mathrm{Fe}_{3} \mathrm{O}_{4}, 34.4 \mathrm{~nm}$ $\mathrm{MgFe}_{2} \mathrm{O}_{4}$, and $130.7 \mathrm{~nm} \mathrm{NiFe} \mathrm{O}_{4}$, exhibited a high temperature rise at lower field strengths.

\subsection{Cytotoxicity study}

The viability of $\mathrm{HeLa}$ cells exposed to $200 \mu \mathrm{g} / \mathrm{ml}$ of $\mathrm{Fe}_{3} \mathrm{O}_{4}(20-30 \mathrm{~nm}), \mathrm{CoFe}_{2} \mathrm{O}_{4}(26.5 \pm 6.1 \mathrm{~nm}), \mathrm{MgFe}_{2} \mathrm{O}_{4}$ $(27.4 \pm 9.2 \mathrm{~nm})$, and $\mathrm{NiFe}_{2} \mathrm{O}_{4}(20-30 \mathrm{~nm})$ nanoparticles is shown in Fig. 5. The viability of HeLa cells exposed to $\mathrm{NiFe}_{2} \mathrm{O}_{4}$ nanoparticles is clearly shown to be extremely low as compared to that of cells exposed to the other nanoparticles. The relative ratio of HeLa cells exposed to $\mathrm{NiFe}_{2} \mathrm{O}_{4}$ nanoparticles for 2 days and 4 days is $52 \%$ and $8 \%$, respectively. It is also found that only HeLa cells exposed to $\mathrm{NiFe}_{2} \mathrm{O}_{4}$ exhibited time dependence in terms of their cell number. The cells exposed to $\mathrm{NiFe}_{2} \mathrm{O}_{4}$ continued to decrease in number because the cell number did not increase, although the number of cells exposed to other nanoparticles remained unchanged for 4 days. $\mathrm{Fe}_{3} \mathrm{O}_{4}$ has been reported to be a biocompatible material $[4,15]$. 


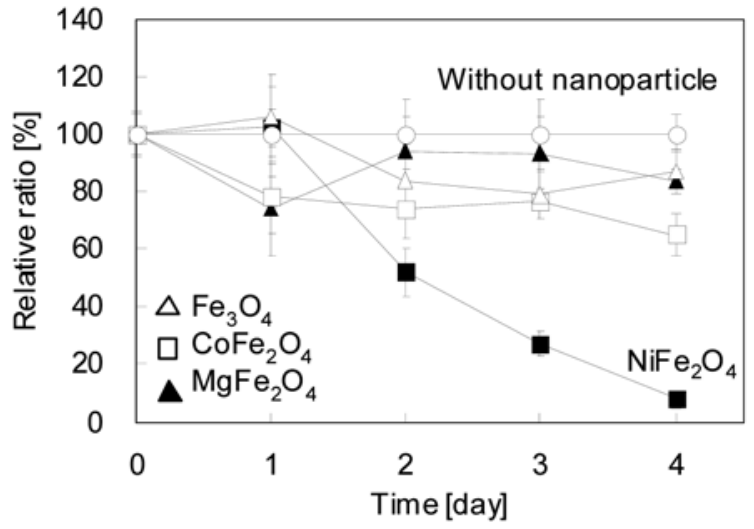

Fig. 5. Relative ratio of HeLa cells treated with and without magnetic nanoparticles at concentration of $200 \mu \mathrm{g} / \mathrm{ml}$ for $\mathrm{Fe}_{3} \mathrm{O}_{4}(20-30 \mathrm{~nm}), \mathrm{CoFe}_{2} \mathrm{O}_{4}(26.5 \pm 6.1 \mathrm{~nm}), \mathrm{MgFe}_{2} \mathrm{O}_{4}(27.4 \pm$ $9.2 \mathrm{~nm})$, and $\mathrm{NiFe}_{2} \mathrm{O}_{4}(20-30 \mathrm{~nm})$ nanoparticles.

The high viability of the cells exposed to $\mathrm{Fe}_{3} \mathrm{O}_{4}$ conforms to these reports. There have been a few reports on the cytotoxicity of $\mathrm{NiFe}_{2} \mathrm{O}_{4}$ nanoparticles. Uncoated nickel ferrite particles $(10 \mathrm{~nm}$ and $150 \mathrm{~nm})$ did not affect the cell viabilities of mouse neuroblastoma cells [16]. However, in our study, $\mathrm{NiFe}_{2} \mathrm{O}_{4}$ nanoparticles greatly reduced the cell viability of HeLa cells. This discrepancy may have been caused by the difference in cell lines.

\section{Conclusion}

In this study, the magnetic characterization, thermal properties, and cytotoxicity of $\mathrm{Fe}_{3} \mathrm{O}_{4}, \mathrm{CoFe}_{2} \mathrm{O}_{4}, \mathrm{MgFe}_{2} \mathrm{O}_{4}$, and $\mathrm{NiFe}_{2} \mathrm{O}_{4}$ nanoparticles were evaluated. $\mathrm{Fe}_{3} \mathrm{O}_{4}$ nanoparticles exhibited a high temperature rise and good biocompatibility. Thus, these nanoparticles are suitable for hyperthermia therapy. $\mathrm{CoFe}_{2} \mathrm{O}_{4}$ nanoparticles can be used as carriers for drug delivery systems because of their large magnetization, which is comparable to that of $\mathrm{Fe}_{3} \mathrm{O}_{4}$ particles, although they are not suitable for hyperthermia therapy because of their poor induction heating ability. $\mathrm{MgFe}_{2} \mathrm{O}_{4}$ nanoparticles are not suitable for biomedical applications because of their low magnetization compared to the other nanoparticles. $\mathrm{NiFe}_{2} \mathrm{O}_{4}$ nanoparticles exhibited a high temperature rise; however, they must be coated with biocompatible materials because of their cytotoxicity to HeLa cells.

\section{References}

[1] Q. A. Pankhurst, J. Connolly, S. K. Jones, and J. Dobson, J. Phys. D: Appl. Phys. 36, R167 (2003).

[2] H. Maeda, G. Y. Bharate, and J. Daruwalla, Eur. J. Pharm. Biopharm. 71, 409 (2009).

[3] H. Nathani and R. D. K. Misra, Mater. Sci. Eng. 94, 228 (2004).

[4] N. Sadeghiani, L. S. Barbosa, L. P. Silva, R. B. Azevedo, P. C. Morais, and Z. G. M. Lacava, J. Magn. Magn. Mater. 289, 466 (2005).

[5] T. Maehara, K. Konishi, T. Kamimori, H. Aono, H. Hirazawa, T. Naohara, S. Nomura, H. Kikkawa, Y. Watanabe, and K. Kawachi, J. Mater. Sci. 40, 135 (2005).

[6] S. Bae, S. W. Lee, and Y. Takemura, Appl. Phys. Lett. 89, 252503 (2006).

[7] A. Tomitaka1, H. Kobayashi1, T. Yamada1, M. Jeun, S. Bae, and Y. Takemura, J. Phys.: Conf. Ser. 200, 122010 (2010).

[8] H. Kobayashi, A. Hirukawa, A. Tomitaka, T. Yamada, M. Jeun, S. Bae, and Y. Takemura, J. Appl. Phys. 107, 09B322 (2010).

[9] S. W. Lee, S. Bae, Y. Takemura, E. Yamashita, J. Kunisaki, S. Zurn, and C. S. Kim, IEEE Trans. Magn. 42, 2833 (2006).

[10] X. Huang and Z. Chen, J. Magn. Magn. Mater. 280, 37 (2004).

[11] V. Sepelak, I. Bergmann, D. Menzel, A. Feldhoff, P. Heitjans, F. J. Litterst, and K. D. Becker, J. Magn. Magn. Mater. 316, e764 (2007).

[12] A. Pardeep, P. Priyadharsini, and G. Chandrasekaran, J. Magn. Magn. Mater. 320, 2774 (2008).

[13] S. Balakrishnan, M. J. Bonder, and G. C. Hadjipanayis, J. Magn. Magn. Mater. 321, 117 (2009).

[14] M. Ma., Y. Wu, J. Zhou, Y. Sun, Y. Zhang, and N. Gu, J. Magn. Magn. Mater. 268, 33 (2004).

[15] P. Pradhan, J. Giri, G. Samanta, H. D. Sarma, K. P. Mishra, J. Bellare, R. Banerjee, and D. Bahadur, J. Biomed. Mater. Res. Part B: Appl. Biomater. 81B, 12 (2007).

[16] H. Yin, H. P. Too, and G. M. Chow, Biomaterials 26, 5818 (2005). 